Mal J Nutr 25(3): 445-461, 2019

\title{
Existence of double burden of malnutrition among Filipino children in the same age-groups and comparison of their usual nutrient intake
}

\author{
Imelda Angeles-Agdeppa ${ }^{*}$, Patricia Isabel Gayya-Amita \& Wargin P. Longalong
}

Food and Nutrition Research Institute - Department of Science and Technology, Taguig City, Philippines

\begin{abstract}
Introduction: This study aimed to determine the prevalence of underweight and overweight children in the same age-groups and if differences existed in their usual nutrients intake. Methods: Data were obtained from 8992 children aged 3-12 years who participated in 2013 National Nutrition Survey. Dietary intake information was collected using two days non-consecutive dietary recall. Usual intakes and distributions of energy and nutrients were estimated in pre-schoolers (3-5 years, $n=2427)$, younger (6-9 years, $n=3594)$ and older schoolchildren (10-12 years, $n=2971$ ) using PC Software for Intake Distribution Estimation (PC-SIDE) from Iowa State University. Energy inadequacy was assessed by the Estimated Energy Requirements (EER) method calculated using the equation of Institute of Medicine. The prevalence of nutrient inadequacy was estimated as the proportion of individuals with usual food intakes below the estimated average requirement (EAR). Results: The prevalence of underweight among preschool, younger and older schoolchildren was $22 \%, 30 \%$ and $16 \%$, respectively, and $4 \%$, 9\% and $10 \%$, respectively, among overweight. The average usual energy and nutrient intake of underweight was significantly lower than overweight. The major source of energy of underweight and overweight was from carbohydrates. However, contribution of fats to total energy was higher among overweight. Most nutrients were below EAR in underweight while only folate (50-79\%) and calcium $(58-84 \%)$ in overweight. Conclusion: The double burden of malnutrition co-exists in children of the same age-groups with higher prevalence nutrient inadequacies in underweight children. Percentage of fat contribution to energy intake was higher among overweight than the underweight.
\end{abstract}

Keywords: Double burden of malnutrition, usual nutrient intake, Filipino children, age-groups

\section{INTRODUCTION}

Rapid changes in diets and lifestyles have occurred in developing countries around the world, as a result of the general improvement of incomes, increasing industrialisation, urbanisation and globalisation (Bishwajit, 2015). Dietary patterns began to shift towards preference for processed foods, the use of edible oils and sugar-sweetened beverages. The intake of legumes, fruits and vegetables has been replaced by high intake of refined carbohydrates, added sugars, fats and foods from

*Corresponding author: Imelda Angeles-Agdeppa, $\mathrm{PhD}$

Food and Nutrition Research Institute, Department of Science and Technology,

DOST Compound, Gen. Santos Ave., Bicutan, Taguig City, Philippines.

Telephone/Fax: 632-8372934; E-mail: iangelesagdeppa@yahoo.com.ph

doi: https://doi.org/10.31246/mjn-2019-0079 
animal sources. All these, together with reduced physical activities, have given rise to a state of nutritional transition (Popkin, Adair \& Ng, 2012).

In the Philippines, this transition has been reflected in changes in the proportions of macronutrient and food intake (Lipoeto, Khor \& Angeles-Agdeppa, 2012). The current patterns of intake of Philippine households show an increase of energy-dense foods and of protein and fats through the consumption of animal foods. The elevated intake of cholesterol and saturated fats in the diet, coupled with sedentary lifestyles, have contributed to the increasing prevalence of overweight among adults, adolescents and children as well (Pedro, Barba \& de Leon, 2008). However, on the other hand, the high rate of undernutrition, especially in children, remains the major nutritional problem in the Philippines. This has resulted in a situation where undernutrition persists together with increasing overnutrition, a phenomenon now known as the double burden of malnutrition (Florentino, Villavieja \& Lana, 2002).

The double burden of malnutrition in children presents a global challenge: in 2014, about 42 million children under the age of five were overweight or obese, 156 million were affected by stunting and 50 million were affected by wasting (WHO, 2014). Among preschool children in the Philippines, the prevalence of underweight decreased slightly from $21 \%$ in 2003 to $20 \%$ in 2013 (FNRI, 2013). Meanwhile, the prevalence of overweight increased from $2 \%$ in 2003 to $5 \%$ in 2013 . The same is true with schoolchildren aged 5-10 years: the prevalence of underweight in 2003 was $32 \%$ and decreased to $29 \%$ in 2013 , while the prevalence of overweight increased from $6 \%$ in 2003 to $9 \%$ in 2013 (FNRI, 2013). Similar trends were seen in Indonesia and China where the prevalence rates of underweight decreased while obesity among schoolaged children increased (Hanandita \& Tampubolon, 2015).

This study aimed to assess the prevalence of the double burden of malnutrition among Filipino children aged 3-12 years old. We evaluated nutrient inadequacies across different age groups and weight status, to determine if there were differences in their usual nutrient intake. We also looked at how socio-economic and geographic differences affected their nutritional status.

\section{MATERIALS AND METHODS}

\section{Study population and variables}

This was a cross-sectional analytical study conducted by the Food and Nutrition Research Institute of the Department of Science and Technology (FNRI-DOST). Data was obtained from the 2013 National Nutrition Survey (NNS). A two, non-consecutive, 24-hour food recall was used to estimate the food intake of individual participants. All members of the households that were sampled were interviewed to collect data for the $1^{\text {st }}$ day and only $50 \%$ of the households were randomly selected to have a $2^{\text {nd }}$ day food recall data. The dietary intake of pre-schoolers (3-5 years old), younger schoolchildren (6-9 years old) and older schoolchildren (10-12 years old) and the demographic characteristics such as national identification (ID) code, age, survey weights, recorded day, weight $(\mathrm{kg})$, height $(\mathrm{m})$ and gender, were extracted from the 2013 NNS data set.

A total of 8,992 children were included in the study: 2,427 of the children were aged 3-5 years, 3594 children 6-9 years and 2971 children 10-12 years. The age groups were aligned with the Philippine Dietary Reference Intake (PDRI) age grouping (FNRI, 2015). 


\section{Measurements}

\section{Dietary}

Face-to-face interview was conducted to obtain information on food that was consumed by an individual over the past 24 hours. The food consumption that was recorded was that starting from the time the subject woke up until bedtime. It included morning, afternoon and late evening (PM) snacks, all food items that were consumed, as well as their description including cooking methods that were used. The amount of each food item and beverage was estimated using common household measurements such as cups, tablespoons, or by size and number of pieces. The Individual Dietary Evaluation System (IDES) was used to evaluate the energy and nutrients content of food consumed by each individual. The estimation of energy and nutrients contents of foods consumed was done using the Updated Philippine Food Composition Table (PhilFCT) that contains 27 nutrients. Details in the development of the Updated PhilFCT will be presented in another publication. The information collected included the name and brand of the food items that were consumed. However, dietary supplements were not included in the survey. Thus, the amount of nutrients consumed were computed based on only the food intake.

\section{Anthropometry}

Weight was measured using the mechanical Detecto ${ }^{\circledR}$ platform beam balance scales and standing height using the Microtoise, which is an L-shaped device (head-bar) to which a spring-loaded coiled tape measure was attached. At least two measurements were obtained to take an average. Weight and height measurements were recorded to the nearest $0.1 \mathrm{~kg}$ and 0.1 $\mathrm{cm}$, respectively. Third measurements were only taken if the difference of the two measurements in weight and height were greater than $0.3 \mathrm{~kg}$ and $0.5 \mathrm{~cm}$, respectively.

\section{Socioeconomic demographic}

A face-to-face interview was conducted to gather data on the socio-economic and demographic variables such as dwelling and household characteristics, and assets. The wealth status of the participants was defined by proxy indicators such as household possession of vehicles, appliances, materials used for housing construction and sanitation facilities. Scores obtained from principal component analysis were used to define wealth quintiles as poorest, poor, middle, rich and richest. Locality was classified as rural and urban by the Philippine Statistical Authority (PSA).

\section{Energy and nutrient evaluation}

Energy and nutrient intakes were scanned to identify implausible values. All processes and evaluations were done for all age groups.

For the evaluation of energy intake, the ratio of daily energy intake to the estimated energy requirement (EER) was calculated for each person per day and then transformed to the logarithmic scale to remove the outliers which defined as values that were $<-3$ SDs and $>+3$ SDs in each age group.

For the evaluation of micronutrient intakes, excessive intakes were substituted by a random value generated from the uniform distribution in the interval of lower bound equal to the $95^{\text {th }}$ percentile of observed intake and upper bound equal to 1.5 times $99^{\text {th }}$ percentile. Excessive micronutrient intakes were defined as those that exceed to 1.5 times the $99^{\text {th }}$ percentile of the observed intake distribution of the corresponding age group.

The distribution of vitamin $\mathrm{B}_{12}, \mathrm{C}$ and $\mathrm{D}$ for all age groups was highly skewed. Hence, we generated and added a small amount of random noise $[\mathrm{N} \sim(0.35,0.05)]$ 
to vitamin $\mathrm{B}_{12}, \mathrm{C}$ and $\mathrm{D}$ intakes to adjust the intakes and rerun the analysis.

\section{Data and statistical analysis}

PC Software for Intake Distribution Estimation (PC-SIDE) version 1.0 was used to compute the mean usual intake distributions of energy and nutrients listed in Table 2 and the prevalence of inadequate and excessive intakes. This software was produced by the researchers of the Department of Statistics at Iowa State University (ISU) in 2001. This programme called the ISU Method (Nusser et al., 1996) has been used to estimate the distributions of usual intake of nutrients, foods consumed almost daily, and other dietary components dietary components. In addition, this programme adjusts the biomarker data for within-person variability (http:// www.side.stat.iastate.edu).

The PDRI was used to evaluate the nutrient inadequacy and excessive intake to determine whether the foods that were consumed provided adequate nutrients to guarantee sufficient growth and development. PDRI was stratified generally by gender. The estimated average requirement (EAR) for male and female were computed for each nutrient to assess the nutrient inadequacy of children.

Prevalence of inadequacy in a group is estimated as the proportion of individuals with usual intakes below the EAR. All nutrients with EARs were assessed using the EAR cut-point method. Nutrients without EAR were saturated fatty acids (SFA), monounsaturated fatty acids (MUFA), polyunsaturated fatty acids (PUFA), dietary fibre, total sugars, vitamin $\mathrm{D}$, vitamin $\mathrm{E}$, magnesium, potassium and sodium (FNRI, 2015).

Total energy intakes were assessed against EER. The EER for each respondent was calculated using the Institute of Medicine's (IOM) equation that takes into account age, sex, body weight $(\mathrm{kg})$, height $(\mathrm{m})$, and physical activity level (PAL). Physical activity of children was assumed as follows: pre-schoolers were sedentary, younger schoolchildren were low active and older schoolchildren were active.

The Acceptable Macronutrient Distribution Ranges (AMDR) reflect the values for carbohydrates (55-79\%), protein (6-15\%) and fats (15-30\%) which are expressed as a percentage of recommended total energy intake of an individual. Values below the recommended range for the specific macronutrient are considered inadequate or low while those above are considered excessive. The derived values reflect the amount of each macronutrient in the total energy intake of the individual to prevent risk of chronic diseases while providing other essential nutrients.

The independent $t$-test and equality of proportion were used to determine the difference the mean intake and prevalence of inadequacy between nutritional statuses of children. For multiple comparisons, we used the Bonferroni correction for adjustment. All $p$-values were 2-tailed and differences were considered statistically significant at $p<0.05$. The nutritional status of children was classified as either underweight or overweight. Pre-schoolers (3-5 years old) and younger schoolchildren (6-9 years old) were classified as underweight if weight-for-age $z$-score (WAZ) was $<-2$ SD. Among older children aged 10-12 years old, underweight was measured using BMI-for-age $z$-score $(\mathrm{BAZ})<-2 \mathrm{SD}$. Pre-schoolers and younger schoolchildren were considered overweight if BMI was > 2SD (BAZ > 2SD) while for the older schoolchildren, BAZ $>1 \mathrm{SD}$ was overweight and $\mathrm{BAZ}>2 \mathrm{SD}$ was considered obese. In this paper, overweight and obesity in this age group are reported as overweight. 


\section{Ethical review}

The 8th NNS Philippines 2013 was submitted to the FNRI Institutional Ethics Review Committee (FNRI-IERC) for clearance. But since it was mandated to define the nutritional status of Filipinos, clearance of the said survey was not necessary. Written consent to participate in the 8th NNS was obtained from the respondents and subjects (through the mother or guardian for children $<10$ years old) prior to the interview and other measurements. The informed consent form explained the background and objectives of the survey, the data collection procedures that were involved, the risks (i.e. any undesirable effect that may result or invasion circumstances, e.g. expected duration of the interview with respondent) and benefits of participation, confidentiality of information, the option to withdraw without penalty or consequences and the respondent's written consent.

\section{RESULTS}

Table 1 shows the demographics of the study population. The prevalence of underweight among pre-school children, younger and older schoolchildren was $22 \%, 30 \%$ and $16 \%$, respectively, and that of overweight was $4 \%, 9 \%$ and $10 \%$, respectively. The proportions of male and female children were similar in all age groups. The mean age for preschoolers, younger school children and older schoolchildren were 4.5, 8.0 and 11.5 years, respectively.

There were significant differences in the socio-economic status and locale of the underweight and overweight children in all age groups. Most of the underweight pre-schoolers $(39 \%)$, younger $(38 \%)$ and older schoolchildren $(26 \%)$ were from the poorest households while overweight pre-schoolers $(46 \%)$, younger $(44 \%)$ and older schoolchildren $(47 \%)$ were from the richest. Most of the underweight pre-schoolers (54\%), younger (59\%) and older (46\%) schoolchildren were from rural area while overweight preschoolers $(61 \%)$, younger $(68 \%)$ and older $(68 \%)$ schoolchildren were from urban areas.

\section{Energy}

The energy intake of underweight children was significantly lower than the intake of overweight children in all age groups $(p<0.05)$. For underweight children, the mean usual intake of pre-schoolers, younger, and older schoolchildren were $873 \pm 1$; $1098 \pm 11$; and $1406 \pm 21 \mathrm{kcal}$, respectively. The average energy intake of the underweight children was $14 \%$, $16 \%$ and $19 \%$ lower than EER among pre-schoolers, younger schoolchildren and older schoolchildren, respectively. The mean usual intakes of pre-schoolers, younger, and older schoolchildren were $1310 \pm 67 ; 1651 \pm 30$; and $1966 \pm 27 \mathrm{kcal}$, respectively. The average energy intake of overweight children pre-schoolers was $4 \%$ higher than EER, 6\% lower among younger schoolchildren and 27\% lower among older schoolchildren (Table 2).

\section{Macronutrients}

The macronutrient intake of underweight children, namely, carbohydrate, protein, total fats, as well as dietary fibre, sugar, SFA, MUFA, and PUFA was significantly lower than the intake of overweight children for all age groups $(p<0.05)$. The inadequate intake of protein among underweight was 16\%, $21 \%$ and $23 \%$, among pre-schoolers, younger schoolchildren and older schoolchildren, campared to that for the overweight which was $6 \%, 2 \%$ and $1 \%$, respectively (Table 2).

\section{As percentage of total energy}

Fat and protein intakes for all age groups, as percentages of total energy, of underweight children were 


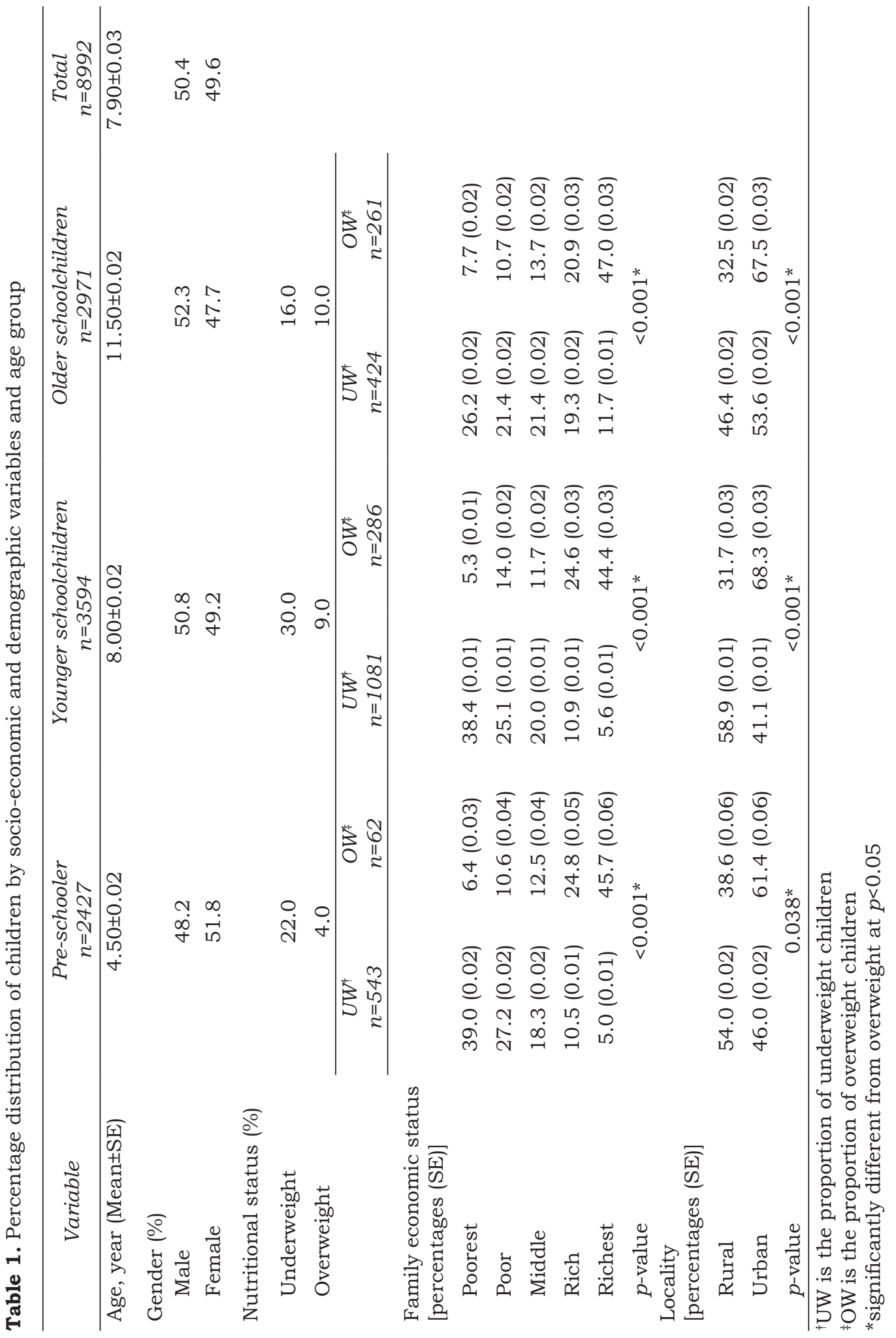


significantly lower than the intakes of overweight $(p<0.05)$. However, the carbohydrate intake of the underweight was significantly higher than that of the overweight $(p<0.05)$. For underweight children, inadequate intake of fat as percentage of total energy was 34\% among pre-schoolers, 52\% among younger schoolchildren and $47 \%$ among older schoolchildren. The inadequate intake of carbohydrates as percentage of total energy was 5\% among preschoolers; $2 \%$ among younger and older schoolchildren. For the overweight children, inadequate intake of fat as percentage of total energy $7 \%$ among pre-schoolers, $11 \%$ among younger schoolchildren and $21 \%$ among older schoolchildren. Inadequate intake of carbohydrates was $24 \%$ among preschoolers and 6\% among younger and older schoolchildren. Protein inadequacy was not observed among children for all age groups (Table 3 ).

\section{Vitamins and minerals}

Vitamin intakes were significantly lower than intakes of overweight children for all age groups. The mineral intake of underweight children was significantly lower than that of the overweight children for all age groups. The mean intake of magnesium and sodium of underweight and overweight children for all age groups were above the recommended intake per day (Table 2 and FNRI, 2015). A high prevalence of inadequate mineral intake was observed for both underweight and overweight children (Table 3).

A high prevalence of inadequate intake was observed for underweight children: vitamin A was $61 \%$ among younger schoolchildren and $63 \%$ among older schoolchildren; thiamine was 56\% among pre-schoolers, 64\% among younger schoolchildren and 74\% among older schoolchildren; riboflavin was $57 \%$ among pre-schooler, 74\% among younger schoolchildren and 83\% among older schoolchildren; vitamin C was 64\% among pre-schoolers, 67\% among younger schoolchildren and 90\% among older schoolchildren; folate was $79 \%$ among pre-schoolers, 68\% among younger schoolchildren and 91\% among older schoolchildren. For overweight children, inadequate intake of folate was $50 \%$ among pre-schoolers and younger schoolchildren and $79 \%$ among older schoolchildren; and vitamin $\mathrm{C}$ was $59 \%$ among younger schoolchildren and $71 \%$ among older schoolchildren.

High prevalence of inadequate intake was observed for underweight children: calcium was $92 \%, 96 \%$ and $95 \%$ among pre-schoolers, younger schoolchildren and older schoolchildren, respectively; iron was $89 \%, 84 \%$ and $97 \%$ among pre-schoolers, younger schoolchildren and older schoolchildren, respectively; phosphorus was 52\% and 96\% among pre-schoolers and older schoolchildren, respectively; and zinc was $64 \%$ among pre-schoolers and 54\% among younger schoolchildren. For overweight children, inadequate intake of calcium was $58 \%$ among pre-schoolers, 84\% among younger schoolchildren and 79\% among older schoolchildren; iron was 58\% among pre-schoolers and 85\% among older schoolchildren; and phosphorus was $72 \%$ among older schoolchildren (Table 2).

\section{Prevalence of inadequacy by location}

Table 4 presents the prevalence of inadequacy of energy and nutrients based on the location of their residence, it being either rural or urban.

\section{Macronutrients}

Prevalence of inadequacy of protein in children who were 3 to 12 years was significantly higher in rural areas in both underweight and overweight. When macronutrients were considered as percentage of the total energy, it was seen that fat inadequacy was higher 


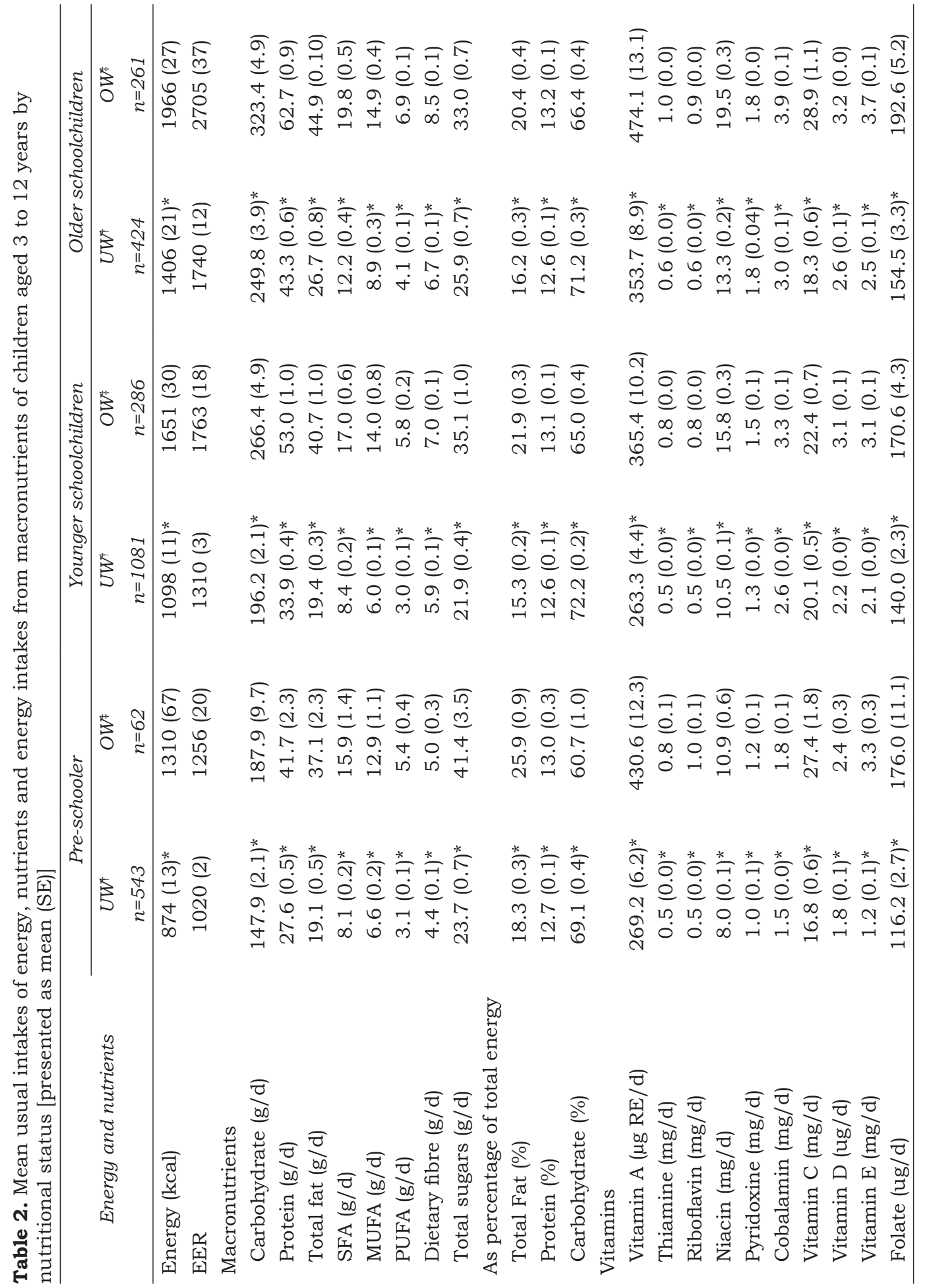




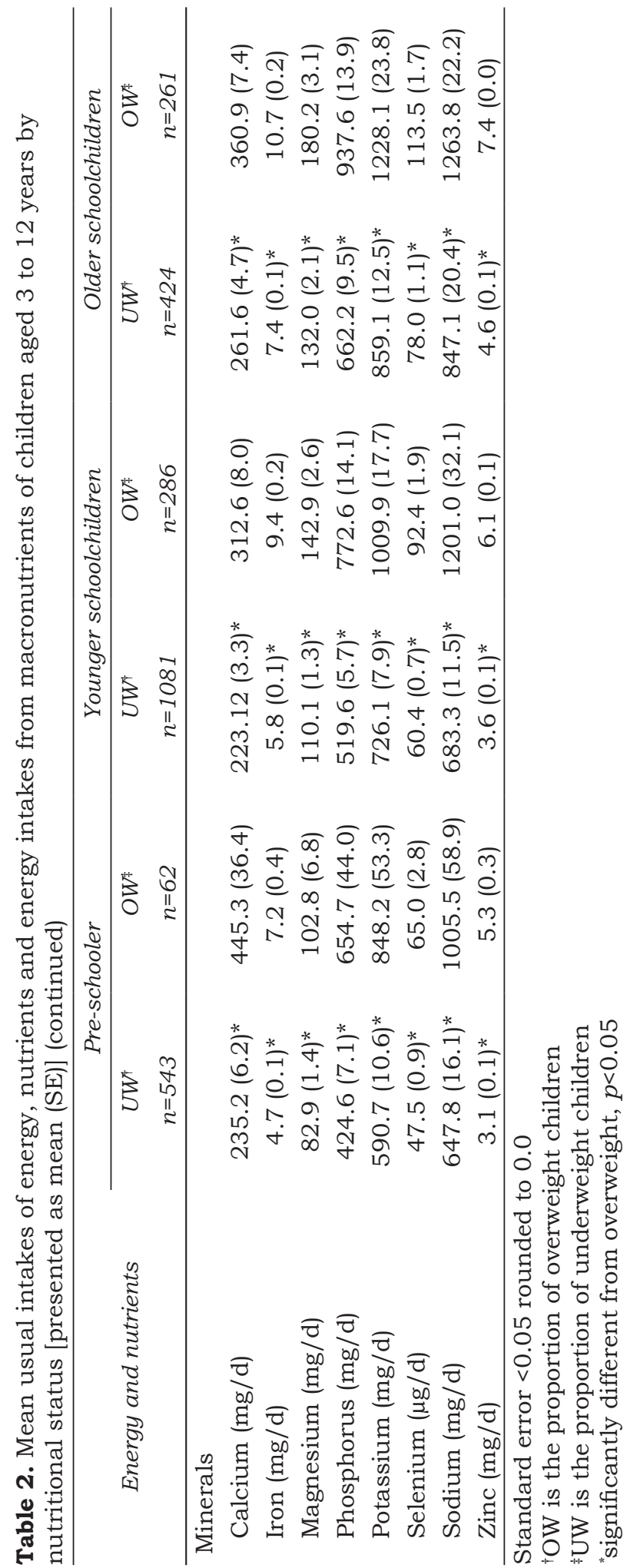




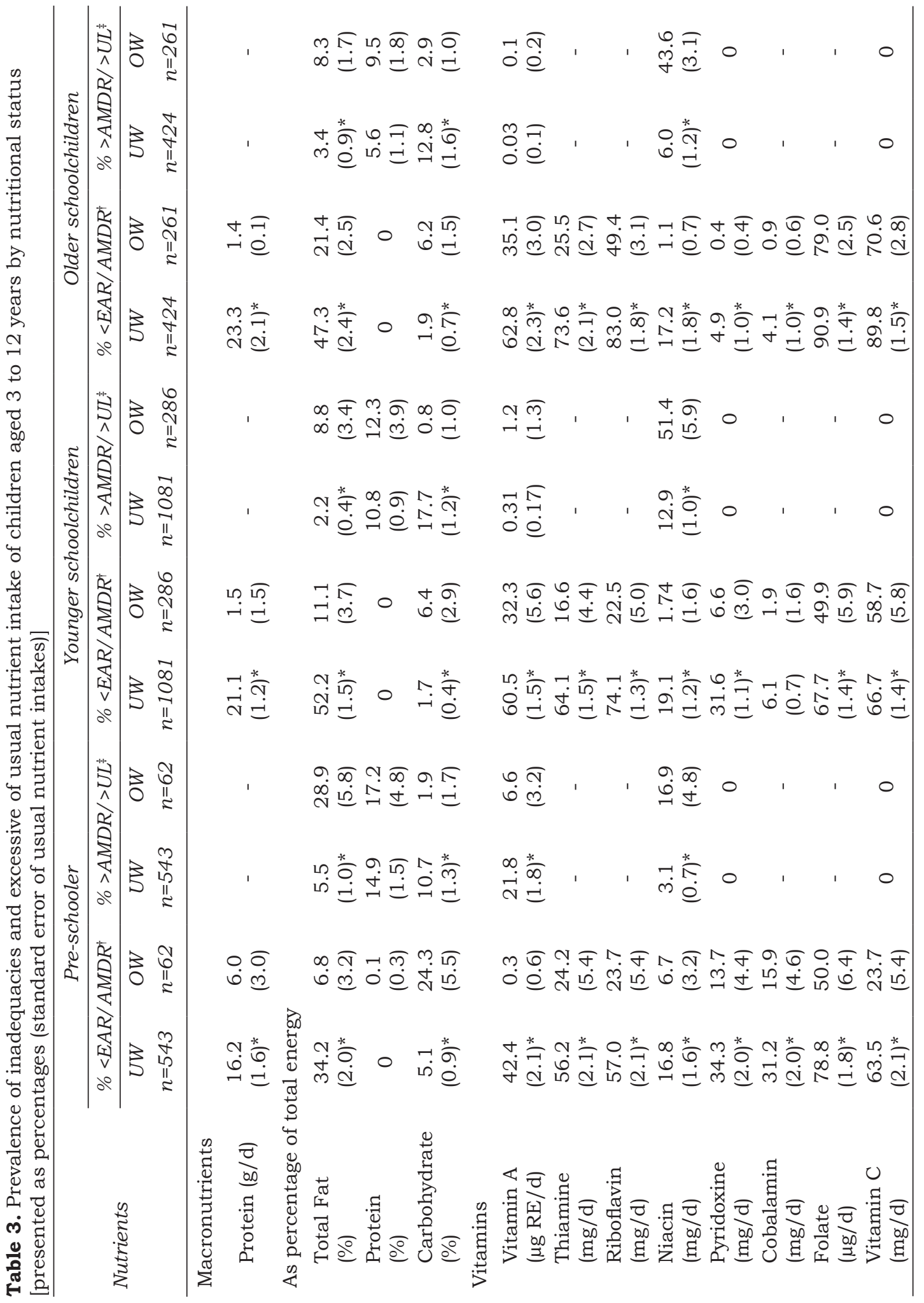




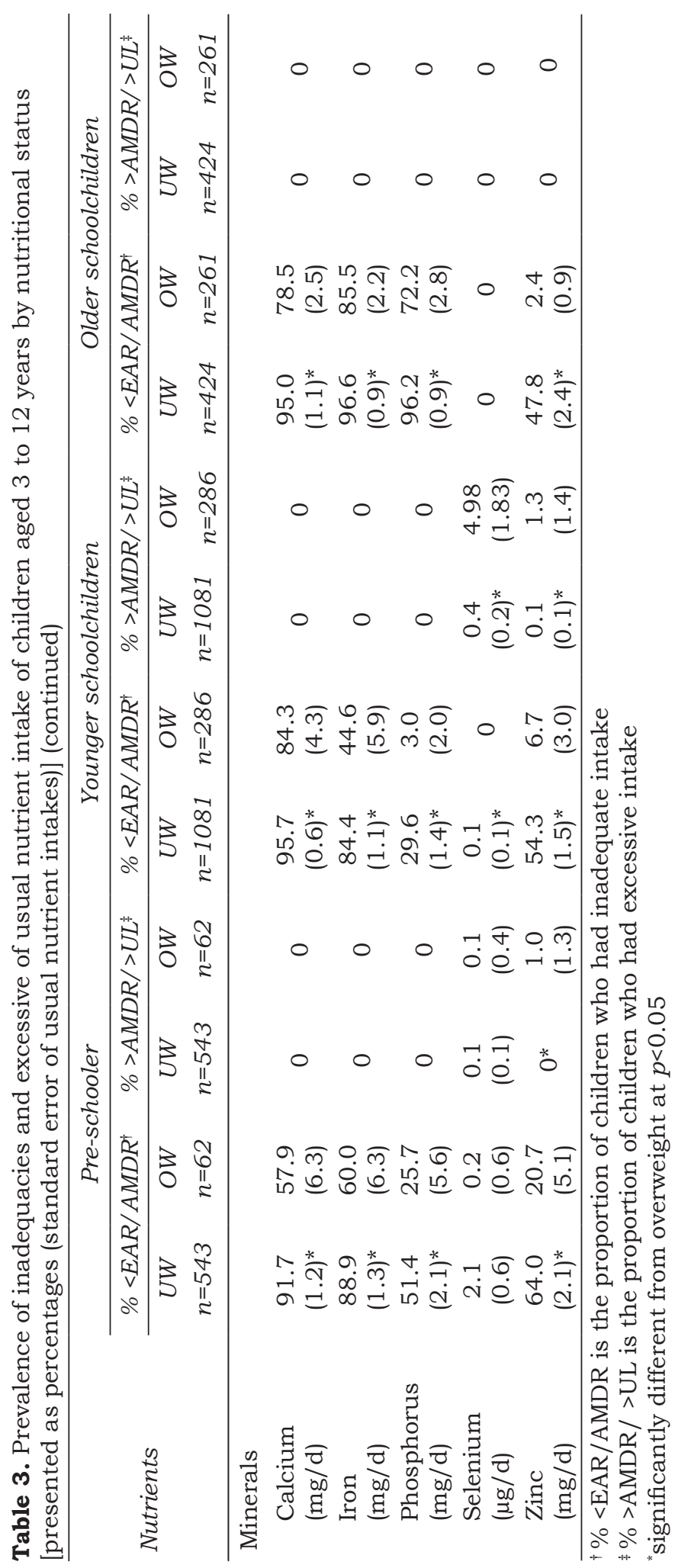


Table 4. Prevalence of inadequacies of nutrients intake of children aged 3-12 years by nutritional status and locality [presented as percentages (standard error of usual nutrient intakes)]

\begin{tabular}{|c|c|c|c|c|}
\hline \multirow[b]{2}{*}{ Nutrients } & \multicolumn{2}{|c|}{ Underweight } & \multicolumn{2}{|c|}{ Overweight } \\
\hline & $\begin{array}{c}\text { Rural } \\
n=1262\end{array}$ & $\begin{array}{l}\text { Urban } \\
n=785\end{array}$ & $\begin{array}{c}\text { Rural } \\
n=244\end{array}$ & $\begin{array}{l}\text { Urban } \\
n=364\end{array}$ \\
\hline \multicolumn{5}{|l|}{ Macronutrients } \\
\hline Protein & $28.0(0.019)^{*}$ & $11.3(0.024)$ & $4.0(0.027)^{*}$ & $1.4(0.011)$ \\
\hline \multicolumn{5}{|c|}{ As $\%$ of the total energy } \\
\hline Fat & $62.0(0.019)^{*}$ & $28.9(0.025)$ & $27.2(0.045)^{*}$ & $6.5(0.040)$ \\
\hline Protein & 0 & 0 & 0 & 0 \\
\hline Carbohydrates & $1.0(0.005)^{*}$ & $5.1(0.017)$ & $5.0(0.032)^{*}$ & $7.6(0.004)$ \\
\hline \multicolumn{5}{|l|}{ Vitamins } \\
\hline Vitamin A & $64(0.026)$ & $61.1(0.031)$ & $33.6(0.078)^{*}$ & $44.3(0.039)$ \\
\hline Thiamin & $75.1(0.021)^{*}$ & $48.8(0.023)$ & $25(0.062)$ & $19.5(0.040)$ \\
\hline Riboflavin & $78.7(0.019)^{*}$ & $59.4(0.020)$ & $38.2(0.038)^{*}$ & $30.5(0.034)$ \\
\hline Niacin & $25.3(0.020)^{*}$ & $9.5(0.027)$ & $3.7(0.026)^{*}$ & $1.1(0.011)$ \\
\hline Vitamin B6 & $39.7(0.020)^{*}$ & $21.9(0.046)$ & $10.6(0.048)$ & $8(0.037)$ \\
\hline Vitamin B12 & $8.5(0.043)$ & $10.6(0.046)$ & $1.2(0.029)^{*}$ & $4.3(0.038)$ \\
\hline Folate & $73.6(0.022)^{*}$ & $79.4(0.038)$ & $63.8(0.045)$ & $57.9(0.039)$ \\
\hline Vitamin C & $67.5(0.030)^{*}$ & $72.6(0.025)$ & $57.7(0.051)$ & $60.3(0.051)$ \\
\hline \multicolumn{5}{|l|}{ Minerals } \\
\hline Calcium & $95.5(0.013)$ & $94.5(0.021)$ & 79 (0.054) & 73 (0.035) \\
\hline Iron & $93.2(0.015)^{*}$ & $81.6(0.031)$ & $66.1(0.039)^{*}$ & $53.4(0.031)^{*}$ \\
\hline Phosphorus & $53.6(0.013)^{*}$ & $43.7(0.018)$ & $30.4(0.033)$ & $25.9(0.028)$ \\
\hline Selenium & $0.6(0.003)$ & $0.1(0.001)$ & 0 & 0 \\
\hline Zinc & $67.5(0.019) *$ & $40.2(0.025)$ & $11.8(0.060)^{*}$ & 4.7 ( 0.029$)$ \\
\hline
\end{tabular}

*Significantly different from urban, $p<0.05$, by using hypothesis testing to compare two population proportions

in rural compared to urban areas but carbohydrate inadequacy was lower in the rural areas for both underweight and overweight.

\section{Vitamins and minerals}

For the underweight, inadequacies in vitamin $B$ such as thiamine, riboflavin, niacin and B6 were higher than rural areas while inadequacies in folate and vitamin $\mathrm{C}$ was lower in rural. For the overweight, inadequacies in vitamin A and B12 were significantly lower in rural areas while inadequacies in riboflavin and niacin were significantly higher in rural.

In regard to minerals, inadequacies for the underweight in iron phosphorus and zinc were significantly higher in rural areas. For the overweight, inadequacies in iron and zinc were significantly higher in rural areas. 


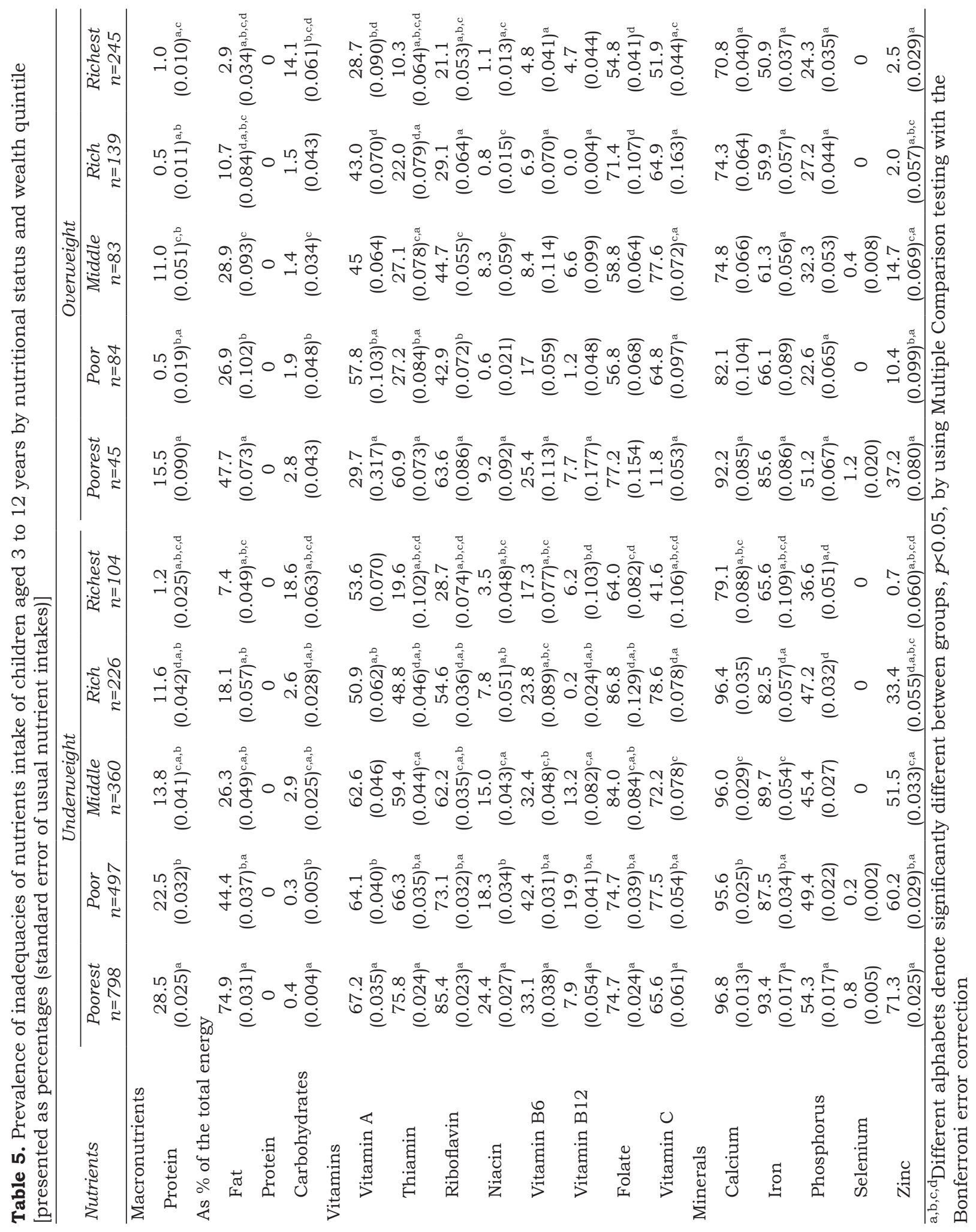




\section{Prevalence of inadequacy by wealth quintile}

Table 5 presents the prevalence of inadequacy of energy and nutrients by the wealth quintile.

\section{Macronutrients}

Inadequacy in protein intake of both underweight and overweight children was significantly higher in the poorest than richest quintile.

As percentage of the total energy, the inadequacy of fat intake was significantly higher in poorest than richest in both underweight and overweight, while that of carbohydrate was significantly lower in poorest than richest.

\section{Vitamins and minerals}

For underweight, inadequacies in vitamin A and B12 intake were significantly higher in poorest than the rich quintile; inadequacy in folate was significantly lower in poorest and richest than rich quintile yet intake of the richest was significantly lower than the middle and rich quintiles; inadequacy in thiamine, riboflavin, niacin, vitamin B6 and vitamin $\mathrm{C}$ were significantly higher in poorest than richest. For overweight, inadequacies in thiamine, riboflavin, niacin, vitamin $\mathrm{B}$ and vitamin $\mathrm{C}$ were significantly higher in poorest than the richest quintile. Inadequacies in calcium, iron, phosphorus and zinc intake were significantly higher in poorest than richest.

\section{DISCUSSION}

The results of this study have shown the existence of the problem of double burden of malnutrition or the co-existence of underweight and overweight among children in the same age groups, as follows: pre-schoolers (underweight $=22 \%$, overweight $=4 \%$ ); younger schoolchildren (underweight $=30 \%$, overweight $=9 \%$ ); older schoolchildren (underweight $=16 \%$, overweight $=10 \%$ ). This is similar with the results of NNS in 2008 to 2013 wherein a slight decrease in the prevalence of underweight among children under-five (21\% to $20 \%$ ) and $5-10$ years $(32 \%$ to $29 \%$ ) was observed and the prevalence of overweight in the same age groups at the same periods has shown a substantial increase $(3 \%$ to $5 \% ; 7 \%$ to $9 \%$ ) (FNRI, 2008; FNRI, 2013).

Oneway tounderstand the occurrence of malnutrition among children is to examine their nutrient intake. Adequate amount of nutrients are essential for an overall optimal health status. Excessive intake can lead to obesity and decreased intake to under-nutrition (Population Reference Bureau, 2006). Based on the findings of this study, the energy intake of underweight children was significantly lower than that of overweight children $(p<0.05)$ in all age groups. A low and inadequate energy intake was also observed in a study in Indonesia which showed underweight children was far below the recommended allowances and lower than that of normal and overweight children (Syahrul et al., 2016).

The observed higher energy intake of the overweight compared with the underweight children is attributed to the higher percentage contribution fats to the total energy although it was still below the AMDR of 15-30\% (FNRI, 2015). The dietary guidelines from the World Health Organization and the Dietary Reference Intakes recommend a total fat intake which is $20-35 \%$ of the total calories (IOM, 2000). While fat is needed for the growth and development of children, the quality of fats that should be consumed must be emphasized (Milner \& Allison, 1999). The higher consumption of SFA of overweight children in our study is a cause of concern because it is a risk factor for cardiovascular diseases (Te Morenga \& Montez, 2017). In addition, the overweight children in our study had almost twice the intake of total sugars 
and sodium, compared with underweight children. This pattern appears to indicate that the consumption of energy-dense foods might, in turn, result in a reduced consumption of nutrient-dense foods. (Tzioumis \& Adair, 2014). The exposure of children to energy-dense, nutrientpoor foods contributes to weight gain and micronutrient deficiencies (Markovic \& Natoli, 2009).

This study has also shown that children belonging to the rich quintiles and who live in urban areas, consume more SFA than those who belong to the poor quantiles and those who live in rural areas. However, in developed countries, an inverse relationship between household income and overweight children was found (Wang $\&$ Lim, 2012). It could be that in developed countries, high-income families tend to purchase healthy and quality food, have time for exercise and other physical activities, and have better access to health care, whereas higher-income households in developing countries buy cheaper energy-dense and nutrientpoor foods that are beyond their needs (Caballero, 2005). Furthermore, a study on overweight children in China showed that the proportion of energy from fat and animal food sources rose with increasing urbanization and household income levels (Zhang et al., 2017). This is similar to a previous study of Filipino schoolchildren in an urban private school which showed higher proportions of overnutrition than undernutrition, since generally children from private schools have higher socio-economic status (Florentino et al., 2002).

The Filipino diet, which is typically high in carbohydrates with large amounts of rice as staple food but low in animal fat, animal protein and fruits and vegetables, carries the risk for micronutrient deficiencies (FNRI, 2013). Our results show that nutrient inadequacies were seen in both underweight and overweight children of all age groups regardless of their mean usual intake. Key nutrients essential for growth and development of children such as thiamine, riboflavin, vitamin $\mathrm{A}$, vitamin $\mathrm{C}$ and zinc were below EAR for underweight children while calcium, iron and folate were below EAR for both overweight and underweight. The 2013 NNS revealed that the prevalence of vitamin A deficiency among children aged $1-5$ and $6-12$ years was $19.6 \%$ and $10.7 \%$, respectively and anemia in the same age groups was $11.2 \%$ and $11.1 \%$, respectively (FNRI, 2013). The prevalence of nutrient inadequacy increases with age (Caballero, 2005). This may be due to dietary practices of younger children as this age group is more dependent on parental control. Parents may be more likely to encourage younger children to eat more to gain weight and height (Tang et al., 2010). Several studies have also shown that a lower dietary adequacy is seen in children with mothers of low educational levels, working mothers with high-ranked occupation and those with poor nutritional knowledge and food related health attitudes (Al-Shookri et al., 2011).

Childhood is a crucial period of physical and cognitive development (Tzioumis \& Adair, 2014). Nutrition programmes aimed at improving dietary behaviour should target both underweight and overweight children from all socio-economic strata and geographical locations since they are all at a great risk for developing micronutrient deficiencies. Undernutrition hinders children's potential for growth. It also contributes to cognitive impairment, resulting in delayed school entry, poor school performance and lower graduation rates (Victora et al., 2008). Childhood obesity on the other hand may eventually lead to the occurrence 
of hypertension, type 2 diabetes mellitus and other non-communicable diseases in adulthood (Goran, Ball \& Cruz, 2003).

This study has provided a comprehensive summary of the differences in the dietary intakes of underweight and overweight Filipino children. The use of mean intakes provided a general overview of nutrient intake levels of the population, while the EAR cut-point method with the national representative sample allowed an estimate of the prevalence of the population with inadequacy intakes. A detailed segmentation of the studied sample by age group, location of residence (i.e. urban or rural) and wealth quintile is essential to ensure tailored nutritional solutions to meet the needs of specific subgroups of the population.

Our study also had several limitations. Firstly, the use of 24-hour recalls to collect dietary intake data relies on the ability of the participants to accurately recall the foods and sizes of the portions that they consumed. Secondly, information on use of dietary supplements was not captured in this study, which could under-estimate the nutrient intakes. Thirdly, the construction of the Filipino FCT involved matching similar food items with established databases such as that of the United States Department of Agriculture (USDA). In reality, however, the nutritional content could be different for similar foods, due to different breed cultivars, climate conditions, mineral abundance in soil and national food fortification policies. Therefore, the findings reported in this study could be subject to measurement errors. If possible, these dietary intake data should be looked at in relation to nutritional biomarkers and health conditions to facilitate better interpretation.

\section{CONCLUSION}

Our result highlights evident findings that under- and overweight coexists within the same age groups of children together with nutrient inadequacies. The percentage of fat contribution to energy intake was higher among the overweight than the underweight. It also indicates that important disparities in socioeconomic status and locality may affect the nutrient intake of children. Clearly, underweight Filipino children belonging to the rural and poorest sectors have inadequate nutrient intake. The same scenario was also seen among overweight children from the urban and richest quintiles. Further research is needed on risk factors that affect nutrient adequacy or inadequacy in both spectrum of nutritional status in different age groups, environmental and socio-cultural settings. Targeted, specific and sensitive nutritional interventions should be implemented and enhanced to control the occurrence of double burden of malnutrition in the country.

\section{Acknowledgement}

The authors would like to thank Keith V. Tanda and Marvin B. Toledo for their technical contributions to the study.

\section{Authors' contributions}

IAA, the project leader in the 2013 NSS, conceptualised and designed the manuscript; PIGA, drafted and reviewed the manuscript; WPL, performed statistical analysis and data interpretation.

\section{Conflict of interest}

The authors declare no conflict of interest in the publication of this article.

\section{References}

Al-Shookri A, Al-Shukaily L, Hassan F, Al-Sheraji S $\&$ Al-Tobi S (2011). effect of mothers nutritional knowledge and attitudes on Omani children's dietary intake. Oman Med $J$ 26(4):253-257. doi:10.5001/omj.2011.61

Bishwajit G (2015). Nutrition transition in South Asia: the emergence of non-communicable chronic diseases. F1000 Research 4:8-8. doi:10.12688/f1000research.5732.2

Caballero B (2005). A nutrition paradox-underweight and obesity in developing countries. N Engl J Med 352(15):1514-1516. doi:10.1056/NEJM p048310 
Florentino RF, Villavieja GM \& Lana RD (2002). Regional study of nutritional status of urban primary schoolchildren. 1. Manila, Philippines. Food Nutr Bull 23(1):24-30. doi:10.1177/156482650202300104

FNRI (2008). 7th National Nutrition Survey. Food and Nutrition Research Institute, Philippines. From https://www.fnri.dost.gov.ph/index. php/ 19-nutrition-statistic/108-7th-nationalnutrition-survey. [Retrieved November 11, 2018].

FNRI (2013). 8th National Nutrition Survey. Food and Nutrition Research Institute, Philippines. From http://enutrition.fnri.dost.gov.ph/site/ preview.php?xx=\%20uploads / 2013 _FaF_ Overview.pdf. [Retrieved November 11, 2018].

FNRI (2015). Philippine Dietary Reference Intakes. Food and Nutrition Research Institute, Philippines.

Goran MI, Ball GD \& Cruz ML (2003). Obesity and risk of type 2 diabetes and cardiovascular disease in children and adolescents. $J$ Clin Endocrin Metab 88(4):1417-1427. doi:10.1210/ jc. 2002-021442

Hanandita W \& Tampubolon G (2015). The double burden of malnutrition in Indonesia: social determinants and geographical variations. SSM - Population Hlth 1:16-25.

IOM (2000). DRI Dietary Reference Intakes: Applications in Dietary Assessment. Institute of Medicine Subcommittee on Interpretation Uses of Dietary Reference Intakes, \& Institute of Medicine Standing Committee on the Scientific Evaluation of Dietary Reference Intakes. National Academies Press (US), Washington DC.

Lipoeto N, Khor GL \& Angeles-Agdeppa I (2012). Food consumption patterns and nutrition transition in South-East Asia. Publ Hlth Nutr. 16(9):1637-43. doi: 10.1017/ S1368980012004569

Markovic TP \& Natoli SJ (2009). Paradoxical nutritional deficiency in overweight and obesity: the importance of nutrient density. Med J Aust 190(3):149-151.

Milner JA \& Allison RG (1999). Role of dietary fat in child nutrition and development: summary of an ASNS workshop. American Society for Nutritional Sciences. J Nutr 129(11):20942105. doi: $10.1093 / j n / 129.11 .2094$

Pedro MR, Barba C \& de Leon R (2008). Nutrition transition in the Philippines. Philipp Popul Rev $6(1)$.
Popkin BM, Adair LS \& Ng SW (2012). Global nutrition transition and the pandemic of obesity in developing countries. Nutr Rev 70(1):3-21. doi:10.1111/j.1753-4887.2011.00456.x.

Population Reference Bureau (2006). The DualBurden of Overweight and Underweight in Developing Countries. From https://www.prb.org/ thedualburdenofoverweightandunderweight in developing countries/. [Retrieved October 7, 2018].

Syahrul S, Kimura R, Tsuda A, Susanto T, Saito R $\&$ Ahmad F (2016). Prevalence of underweight and overweight among school-aged children and it's association with children's sociodemographic and lifestyle in Indonesia. Int $J$ Nurs Sci 3(2):169-177. doi: 10.1016/j. ijnss.2016.04.004

Tang KH, Nguyen HH, Dibley MJ, Sibbritt DW, Phan NT \& Tran TM (2010). Factors associated with adolescent overweight/obesity in Ho Chi Minh city. Int $J$ Ped Obesity 5(5):396-403. doi:10.3109/17477160903540735

Te Morenga L \& Montez JM (2017). Health effects of saturated and trans-fatty acid intake in children and adolescents: Systematic review and metaanalysis. PloS One 12(11):e0186672-e0186672. doi:10.1371/journal.pone.0186672

Tzioumis E \& Adair LS (2014). Childhood dual burden of under- and overnutrition in lowand middle-income countries: a critical review. Food Nutr Bull 35(2):230-243. doi:10.1177/156482651403500210

Victora CG, Adair L, Fall C, Hallal PC, Martorell R, Richter L \& Sachdev HS (2008). Maternal and child undernutrition: consequences for adult health and human capital. The Lancet 371(9609):340-357. doi:10.1016/S0140-6736 (07)61692-4

Wang Y \& Lim H (2012). The global childhood obesity epidemic and the association between socio-economic status and childhood obesity. Int Rev Psych 24(3):176-188. doi:10.3109/095 40261.2012.688195

WHO (2014). Double burden of malnutrition. World Health Organization. From https://www.who. int/nutrition/double-burden-malnutrition/ en/. [Retrieved December 12 2018].

Zhang J, Wang D, Eldridge AL, Huang F, Ouyang Y, Wang H \& Zhang B (2017). Urban-rural disparities in energy intake and contribution of fat and animal source foods in Chinese children aged 4-17 years. Nutrients 9(5). doi:10.3390/ nu9050526 